\title{
Modifying the request behaviour of clinicians
}

\author{
R Gama, P G Nightingale, P M G Broughton, M Peters, J G Ratcliffe, G V H Bradby, \\ J Berg
}

\author{
Department of \\ Clinical Chemistry, \\ Wolfson Research \\ Laboratories, Queen \\ Elizabeth Medical \\ Centre, Birmingham \\ R Gama, \\ P G Nightingale, \\ P M G Broughton \\ M Peters, \\ J G Ratcliffe \\ Department of \\ General Medicine, \\ Sandwell District \\ General Hospital, \\ West Bromwich \\ G V H Bradby \\ Department of \\ Clinical Chemistry, \\ Sandwell District \\ General Hospital \\ J Berg \\ Correspondence to: \\ Dr R Gama, Department of \\ Chemical Pathology, Epsom \\ District Hospital, Dorking \\ Road, Epsom, Surrey \\ KT18 7EG \\ Accepted for publication \\ 27 August 1991
}

\begin{abstract}
Aim: To evaluate whether the feedback of laboratory use and cost data to clinicians modifies their request behaviour.

Methods: Over two years the effect of monthly feedback of clinical chemistry test use and revenue expenditure to three consultant physicians on their clinical chemistry and haematology requesting patterns was evaluated. Two physicians who received no information served as controls.

Results: Feedback over one year led to an immediate and sustained decrease of $15 \%, 27 \%$, and $21 \%$ in clinical chemistry requests $(p<0.01)$, tests $(p<0.001)$, and revenue expenditure $(p<0.001)$, respectively, and a $10 \%$ reduction in haematology tests $(p<0.05)$ per outpatient visit. These changes persisted in the six months after the feedback was stopped.

Conclusions: These results suggest that feedback of laboratory data to clinicians modifies their request behaviour and that supplying clinicians with information on what they do can influence the way they make decisions.
\end{abstract}

Several strategies for improving laboratory use have been proposed but none has been widely adopted. ${ }^{12}$ Although feedback of laboratory data to clinicians has been deemed ineffective, ${ }^{2}$ we have reported preliminary results suggesting that feedback is effective in changing the request behaviour of physicians. Over six months, the feedback of clinical chemistry laboratory data to general physicians led to a reduction in their clinical chemistry requests and expenditure on outpatients but not on inpatients. ${ }^{3}$

Most other "successful" strategies have either initiated change but been unable to maintain it, or have been too brief to evaluate long term effects. ${ }^{12}$ We therefore carried out a two year prospective controlled study evaluating the effect of laboratory feedback over one year and continued follow up for a further six months after stopping the feedback. Unknown to the physicians, we also evaluated the indirect effect of feedback of clinical chemistry data on their haematology requesting patterns.

\section{Methods}

The study was undertaken at Sandwell District General Hospital with approval from the medical executive committee.
Data on clinical chemistry test use and revenue expenditure per admission or per outpatient visit, were supplied monthly to three consultant physicians. ${ }^{3}$ The data were provided as eight histograms on four sheets of A4 paper. The first sheet compared clinical chemistry use and expenditure among the physicians on inpatients for that month. The other sheets provided data for the previous 12 months comparing each physician's use and expenditure with the mean of the other four physicians. These data were separated into within hours and out of hours for inpatients and for outpatients. Two consultant physicians who received no information served as controls. Unknown to the physicians, we also collected data on their haematology requests throughout the study period and on their clinical chemistry requests and costs after feedback had stopped. A request was defined as any number of samples taken from a patient at any one time and sent to the laboratory for one or more analyses (tests).

Changes in the feedback and control groups were assessed by comparing laboratory use and expenditure before (baseline) (01.11.88 to 30.04 .89 ), during (intervention) (01.05.89 to $30.0490)$, and after (follow up) (01.05.90) to 31.10.90) the feedback using the Mann-Whitney $U$ test. $P$ values of $<0.05$ were regarded as significant.

\section{Results}

The numbers of emergency admissions and new outpatient visits in the intervention $(92 \%$ and $21 \%$, respectively) and control (88\% and $10 \%$, respectively) groups remained unchanged throughout the three study periods.

In the baseline period the variation in the physicians' clinical chemistry requests on inpatients was 1.5-fold and 3.6-fold on outpatients.

In the one year intervention period, there was an immediate and sustained decrease of $15 \%, 27 \%$, and $21 \%$ in clinical chemistry requests $(p<0.01)$, tests $(p<0.001)$, and expenditure $(p<0.001)$, respectively, and a $10 \%$ reduction in haematology tests $(p<0.05)$ per outpatient visit in the intervention group. These changes persisted in the six months after the feedback had stopped (tables 1 and 2). There were no significant decreases for inpatients in the intervention and control groups (tables 1 and 2).

The cost of providing the feedback was $£ 530$ a year. The corresponding annual savings in revenue expenditure and cash (consumable costs) achieved through a reduction in out- 
patient chemistry usage were $£ 3027$ and $£ 560$, respectively.

\section{Discussion}

The reduction in clinical chemistry usage and costs on outpatients which persisted after feedback had stopped suggests that the feedback of laboratory data to clinicians both achieves and sustains change. A possible reason for this is that comparative feedback involves continuous reinforcement or admonition of current behaviour and therefore provides a continuing stimulus for change.

The fact that fewer outpatients were investigated, and when investigated had fewer tests performed on them, supports the view that the physicians had become more judicious in their laboratory use.

Although not provided with haematology

Table 1 Clinical chemistry use and expenditure during baseline, intervention and follow up periods

\begin{tabular}{|c|c|c|c|}
\hline & Baseline & Intervention & Follow up \\
\hline \multicolumn{4}{|c|}{ Requests/outpatient visit: } \\
\hline Feedback & $0.5(0.4-0.5)$ & \multirow{2}{*}{$\begin{array}{l}\mathrm{a}^{\star \star} \\
0.4(0.4-0.5) \\
\mathrm{a} \mathrm{NS} \\
0.8(0.2-1.0)\end{array}$} & \multirow{2}{*}{$\begin{array}{l}\mathrm{a}^{\star \star} \mathrm{bNS} \\
0.4(0.4-0.5) \\
\mathrm{a} N S \mathrm{~b} \text { NS } \\
0.8(0.2-1.0)\end{array}$} \\
\hline Control & $0 \cdot 7(0 \cdot 2-1 \cdot 0)$ & & \\
\hline \multicolumn{4}{|c|}{ Tests/outpatient visit: } \\
\hline Feedback & $3 \cdot 7(2 \cdot 9-4 \cdot 4)$ & \multirow{2}{*}{$\begin{array}{l}\mathrm{a}^{\star \star \star} \\
2 \cdot 7(2 \cdot 6-2 \cdot 8) \\
\mathrm{a} \mathrm{NS} \\
1 \cdot 3(1 \cdot 1-1 \cdot 5)\end{array}$} & \multirow{2}{*}{$\begin{array}{l}a^{\star \star} \text { bNS } \\
2 \cdot 7(2 \cdot 5-3 \cdot 1) \\
\text { a NS b NS } \\
1 \cdot 3(0 \cdot 7-2 \cdot 0)\end{array}$} \\
\hline Control & $1 \cdot 3(1 \cdot 2-1 \cdot 3)$ & & \\
\hline \multicolumn{4}{|c|}{ Tests/request (outpatients): } \\
\hline Feedback & $7 \cdot 8(5 \cdot 6-9 \cdot 9)$ & \multirow{2}{*}{$\begin{array}{l}\mathrm{a}^{\star \star} \\
6 \cdot 7(5 \cdot 7-7 \cdot 4) \\
\mathrm{a} \mathrm{NS} \\
1 \cdot 7(1 \cdot 4-5 \cdot 3)\end{array}$} & \multirow{2}{*}{$\begin{array}{l}a^{\star \star} b \text { NS } \\
6 \cdot 7(5 \cdot 7-7 \cdot 9) \\
\text { A NS b NS } \\
1 \cdot 7(1 \cdot 4-4 \cdot 9)\end{array}$} \\
\hline Control & $1 \cdot 7(1 \cdot 4-5 \cdot 5)$ & & \\
\hline \multicolumn{4}{|c|}{ Revenue expenditure/outpatient visit ( $£$ ) } \\
\hline Feedback & $2 \cdot 3(2 \cdot 0-2 \cdot 6)$ & \multirow{2}{*}{$\begin{array}{l}a^{\star \star \star} \\
1 \cdot 8(1 \cdot 8-2 \cdot 0) \\
a \mathrm{NS} \\
1 \cdot 6(0 \cdot 8-2 \cdot 4)\end{array}$} & \multirow{2}{*}{$\begin{array}{l}\mathrm{a}^{\star \star \star} \mathrm{b} \text { NS } \\
1 \cdot 8(1 \cdot 6-2 \cdot 1) \\
\mathrm{a} \text { NS b NS } \\
1 \cdot 6(0 \cdot 7-2 \cdot 7)\end{array}$} \\
\hline Control & $1.5(0.9-1.8)$ & & \\
\hline \multicolumn{4}{|c|}{ Requests/admission } \\
\hline Feedback & $2 \cdot 3(2 \cdot 0-2 \cdot 6)$ & \multirow{2}{*}{$\begin{array}{l}\text { a NS } \\
2 \cdot 4(1 \cdot 9-2 \cdot 8) \\
\text { a NS } \\
2 \cdot 6(2 \cdot 6-2 \cdot 7)\end{array}$} & \multirow{2}{*}{$\begin{array}{l}\text { a NS b NS } \\
2 \cdot 3(1 \cdot 9-2 \cdot 6) \\
\text { a NS b NS } \\
2 \cdot 8(2 \cdot 7-3 \cdot 0)\end{array}$} \\
\hline Control & $2 \cdot 5(2 \cdot 4-2 \cdot 6)$ & & \\
\hline \multicolumn{4}{|c|}{ Tests/admission } \\
\hline Feedback & $14 \cdot 7(11 \cdot 5-17 \cdot 4)$ & \multirow{2}{*}{$\begin{array}{l}\text { a NS } \\
15 \cdot 2(11 \cdot 6-18 \cdot 0) \\
\text { a NS } \\
16 \cdot 0(15 \cdot 1-16 \cdot 7)\end{array}$} & \multirow{2}{*}{$\begin{array}{l}\text { a NS b NS } \\
15 \cdot 6(12 \cdot 9-20 \cdot 4) \\
a^{\star \star} b^{\star} \\
18 \cdot 4(17 \cdot 0-19 \cdot 7)\end{array}$} \\
\hline Control & $14 \cdot 5(14 \cdot 3-14 \cdot 7)$ & & \\
\hline \multicolumn{4}{|c|}{ Revenue expenditure/admission ( $£$ ) } \\
\hline Feedback & $11 \cdot 1(9 \cdot 2-12 \cdot 3)$ & \multirow{2}{*}{$\begin{array}{l}\text { a NS } \\
11 \cdot 8(9 \cdot 2-13 \cdot 6) \\
\text { a NS } \\
12 \cdot 9(12 \cdot 6-13 \cdot 2)\end{array}$} & \multirow{2}{*}{$\begin{array}{l}\text { a NS b NS } \\
11.5(9 \cdot 5-14 \cdot 7) \\
a^{\star} b \text { NS } \\
14 \cdot 0(13 \cdot 6-14 \cdot 4)\end{array}$} \\
\hline Control & $11 \cdot 7(11 \cdot 1-12 \cdot 6)$ & & \\
\hline
\end{tabular}

Results are means with ranges in parentheses.

$a$ and $b$ are compared to baseline and intervention periods, respectively

${ }^{\star} \mathrm{p}<0.05,{ }^{\star \star} \mathrm{p}<0.01,{ }^{\star \star \star} \mathrm{p}<0.001$. NS $\mathrm{p}>0.05$.

Table 2 Haematology use and expenditure during baseline, intervention and follow up periods

\begin{tabular}{|c|c|c|c|}
\hline & Baseline & Intervention & Follow up \\
\hline \multicolumn{4}{|c|}{ Tests/outpatient visit } \\
\hline Feedback & $1.4(0.5-2.5)$ & $\begin{array}{l}a^{\star} \\
1 \cdot 3(0 \cdot 5-2 \cdot 0) \\
a N S\end{array}$ & $\begin{array}{l}a^{\star} \text { b NS } \\
1.3(0.5-2 \cdot 0)\end{array}$ \\
\hline Control & $0 \cdot 1(0 \cdot 1-0 \cdot 2)$ & $0 \cdot 1(0 \cdot 1-0 \cdot 2)$ & $0 \cdot 1(0 \cdot 1-0 \cdot 1$ \\
\hline \multicolumn{4}{|c|}{ Tests/admission } \\
\hline Feedback & $2 \cdot 0(1 \cdot 9-2 \cdot 2)$ & $\begin{array}{l}\text { a NS } \\
2 \cdot 2(2 \cdot 0-2 \cdot 4) \\
a^{\star}\end{array}$ & $\begin{array}{l}\text { a NS b NS } \\
1.9(1 \cdot 8-2 \cdot 1) \\
a^{\star} b N S\end{array}$ \\
\hline Control & $1.7(1.7-1.8)$ & $2 \cdot 3(2 \cdot 0-2 \cdot 60)$ & $2 \cdot 3(1 \cdot 9-2 \cdot 6)$ \\
\hline
\end{tabular}

Results are means with ranges in parentheses.

$a$ and $b$ are compared to baseline and intervention periods, respectively.

${ }^{\star} \mathrm{p}<0.05$, NS $\mathrm{p}>0.05$ data, the physicians in the intervention group also reduced their haematology usage on outpatients. This and the sustained effect after the feedback was stopped suggests that the feedback had modified the physicians' behaviour towards laboratory testing.

The lack of effect on inpatients was probably because the data were not directly supplied to junior medical staff, who requested almost all inpatient tests. The aim of feedback is to influence the decision makers and it may be that feedback should have been provided at this level. An alternative explanation is that the wider variation on outpatient laboratory usage may have been the motivation for change. This is one limitation of providing comparative data in that when there is only a small variation, such as on inpatient usage in this study, there is little incentive to change.

As expected, the cash savings through reducing laboratory workload were small. ${ }^{4}$ If, however, feedback were extended to a larger group the cash savings would increase proportionately (not including indirect effects on other diagnostic services such as haematology), but the "extra costs" would still be relatively small.

Several strategies for improving laboratory usage have been proposed. ${ }^{12}$ The potential advantages $^{3}$ of this approach are that:

(1) it makes no assumptions about which tests are or are not necessary-in practice there are only a few tests which are never effective;

(2) it is free from externally imposed standards and therefore not threatening to the clinician;

(3) it recognises that clinical practice is dynamic with no explicit ideal;

(4) it provides data essential to medical audit, clinical budgeting and resource management;

(5) it monitors laboratory use and can be used alone or to complement other strategies;

(6) it can easily be automated.

In conclusion, feedback of laboratory use and cost data was acceptable to the physicians, laboratory personnel, and hospital information officers. It modified the requesting behaviour of the physicians studied and resulted in an immediate and sustained reduction in laboratory workload and expenditure. These changes persisted for at least six months after the feedback had stopped. This approach, at the clinicians' request, has now been extended to the whole hospital.

RG, PGN, and MP acknowledge financial support from the Department of Health. We thank Peter Boston and Barbara Field for their help in collecting data, the medical staff for participating in the study, and Dr P Stableforth for allowing us access to haematology data.

1 Young DW. Improving laboratory usage: a review. Postgrad Med $J$ 1988;64:283-9.

2 Fraser CG, Woodford FP. Strategies to modify the test requesting patterns of clinicians. Ann Clin Biochem 7:24:223-31.

3 Gama R, Nightingale PG, Broughton PMG, et al. Feedback of laboratory usage and cost data to clinicians: Does it alter requesting behaviour? Ann Clin Biochem 1991;28:143-9. 4 Winkleman JW. Less utilisation of the clinical laboratory produces disproportionately small true cost reductions.
Hum Pathol 1984;82:418-23. 